\title{
ALAT BANTU SURVEY BAWAH AIR MENGGUNAKAN AMOBA, ROBOT BERBASIS ROV
}

\author{
Made Santo Gitakarma ${ }^{1}$, Ketut Udy Ariawan $^{2}$, Nyoman Arya Wigraha ${ }^{3}$ \\ 1Jurusan Pendidikan Teknik Elektro, ' Jurusan Pendidikan Teknik Mesin, \\ Fakultas Teknik dan Kejuruan Undiksha, Singaraja \\ e-mail: santo@undiksha.ac.id
}

\begin{abstract}
Abstrak
Tujuan yang ingin dicapai dalam penelitian ini adalah 1) menghasilkan rancangan prototipe robot alat monitor dan observasi bawah air (AMOBA) berbasis ROV (remotely operated vehicle) yang mampu bergerak di dalam air; 2) melakukan uji coba prototipe robot AMOBA di bawah air dan mengkaji hasilnya; 3) memperoleh kinerja prototipe robot AMOBA sebagai alat yang memiliki kemampuan survey (monitoring and observation) bawah air. ROV merupakan robot bawah air yang dikendalikan oleh operator dalam pengoperasiannya, dan didukung oleh perangkat kendali dalam pengoperasiannya. Pada penelitian ini dikembangkan prototipe ROV yang mampu bernavigasi di bawah air dengan kendali berbasis mikrokontroller dari permukaan air menggunakan kabel $15 \mathrm{~m}$ dan beberapa aktuator dengan propellernya dari pompa air. Pompa air yang digunakan sebanyak 8 buah (2 buah pompa untuk belok kiri, 2 buah pompa untuk belok kanan, 2 buah pompa untuk maju ke depan, dan 2 buah pompa untuk naik ke atas). Robot AMOBA yang dikembangkan dilengkapi dengan IPCamera yang dapat dikendalikan untuk menampilkan visual bawah air dan dapat diputar sepanjang $120^{\circ}$ (kiri, kanan, atas, dan bawah). Metode yang akan digunakan untuk mencapai tujuan diatas adalah metode penelitian dan pengembangan (research and development) atau R\&D menurut Borg dan Gall. Analisis dalam penelitian ini menggunakan konsep SMART (specific, measurable, achievable, realistic, time-based). Hasil penelitian menunjukkan rata-rata kecepatan robot $21,5 \mathrm{~cm} /$ detik dengan bobot $23 \mathrm{~kg}$. Kecepatan robot tergolong lambat dan saat pergerakan di awal pelan kemudian perlahan-lahan cepat akibat perlunya daya yang kuat untuk mendorong robot di awal. Semakin dalam robot di air maka tekanan air semakin besar dan berakibat terhentinya pompa air bekerja. Pompa air yang digunakan hanya dapat bekerja maksimal hingga kedalaman $3 \mathrm{~m}$. Sehingga diperlukan aktuator dengan propeller yang lebih kuat apabila ingin dikembangkan untuk menjangkau kedalaman air lebih dari $3 \mathrm{~m}$.
\end{abstract}

Kata kunci: ROV, survey, robot bawah air, sistem navigasi, kelautan

\begin{abstract}
The objectives of this research are 1) produce a prototype design of monitoring tools and robotic underwater observation (AMOBA) based ROV (remotely operated vehicle) that is able to move in the water; 2 ) to test the prototype underwater robot AMOBA and reviewing the results; 3 ) obtaining performance of the prototype robot
\end{abstract}


AMOBA as a tool that has the ability to survey (monitoring and observation) underwater. ROV is an underwater robot that is controlled by the operator in the operation, and is supported by the control device in operation. In this research, a prototype of ROV developed that is capable of navigating underwater with a microcontroller-based control from surface using a $15 \mathrm{~m}$ cable and some actuators with propeller from the water pump. 8 pieces water pumps are used 2 pieces pump to turn left, 2 pumps to turn right, 2 pumps to move forward, and 2 pieces of the pump to rise to the top). AMOBA robot equipped with IPCamera that can be controlled for visual display under water and can be played throughout 120 degrees (left, right, top, and down). Methods to be used to achieve the above objectives is a method of research and development) or R \& D according to Borg and Gall. The analysis in this study uses the concept of SMART. The results showed the average speed of the robot $21.5 \mathrm{~cm} / \mathrm{sec}$ and weight $23 \mathrm{~kg}$. Speed of the robot is slow in the beginning and then slowly became faster due to the need for strong power to push robot in the beginning. The deeper the water, the robots in the greater water pressure and the resulting cessation of the water pump works. The water pump used can only work a maximum of up to a depth of $3 \mathrm{~m}$. So that the necessary stronger actuator if you want to be developed to reach water depths of more than $3 \mathrm{~m}$.

Keywords : ROV, survey, underwater robots, navigation systems, marine

\section{PENDAHULUAN}

Teknologi komputer, terutama robotika di masa sekarang sudah menjadi bagian penting dalam kehidupan manusia. Robot adalah peralatan eletro-mekanik atau biomekanik, atau gabungan peralatan yang menghasilkan gerakan yang otonomi maupun gerakan berdasarkan gerakan yang diperintahkan (Halim, 2007). Robot dalam beberapa hal dapat menggantikan peran manusia, hal ini terlihat pada robot-robot yang diterapkan dalam berbagai bidang seperti industri, kesehatan (health), pertahanan (defense), pertanian (agriculture), penelitian (research), pemainan (game), dan lain-lain.

Dalam industri modern, robot telah mengambil alih posisi para pekerja di pabrik-pabrik. Misalnya dalam industri automotif, alat elektronik, peranti komputer, robot telah menjadi penggerak utama dari industri ini.
Alasan utama penggunaan robot adalah karena, robot dalam kondisi tertentu (syarat minimum operasi terpenuhi) dapat menjadi pekerja yang ideal, robot memiliki tingkat akurasi dan efisiensi yang tinggi, serta yang lebih penting adalah biaya operasinya rendah dengan output yang dihasilkan lebih tinggi.

Ada beberapa tipe robot, yang secara umum dapat dibagi menjadi dua kelompok yakni robot manipulator dan robot mobil (mobile robot). Robot manipulator dicirikan dengan memiliki lengan (arm robot), dan banyak digunakan untuk robot industri. Sedangkan robot mobil merupakan robot yang dapat bergerak berpindah tempat, meskipun nantinya robot tersebut juga dipasang manipulator. Robot mobil dapat dikelompokkan lagi menjadi tiga yaitu robot daratan (ground robot), robot air (underwater robot), dan robot terbang (aerial robot). Ketiga jenis robot ini sangat banyak dikembangkan 
pada saat sekarang ini karena melihat sifatnya yang sangat fungsional.

Pada penelitian ini akan dikembangkan robot monitor bawah air (integrated underwater vehicle) dengan berbasis sistem ROV (remotely operated vehicle). Secara sederhana cara kerja dari robot berbasis ROV adalah dioperasikan menggunakan sistem yang dikendalikan oleh pengguna melalui perangkat kontroler. Sistem kamera video bawah air juga akan dipasang pada wahana aktif tak berawak ini yang dikendalikan dari jauh. Sistem kendali robot dan robot itu sendiri dihubungkan dengan media transmisi data seperti kabel atau gelombang radio (RF=Radio Frequency).

Beberapa penelitian tentang sistem ROV telah dibahas di luar negeri seperti (E. Kelner, 2012) yang mengembangkan sistem sampling data ROV di kedalaman laut dan penelitian (Enfang S, 2005) implementasi sonar untuk pendeteksian bawah laut dengan ROV. Alasan kenapa pada penelitian ini penulis mengangkat tema robot monitor bawah air, adalah karena robot ini belum banyak dikembangkan dan mungkin kurang mendapat perhatian, khususnya di Indonesia. Hal ini sangat ironis dan bertolak belakang dengan kondisi geografis Indonesia, dimana Indonesia adalah negara yang memiliki perairan yang sangat luas dan mengandung nilai potensi ekonomi yang sangat besar. Keterbatasan kemampuan manusia untuk memetakan potensi bawah laut Indonesia terutama untuk kawasan laut dalam yang belum terjamah. Untuk menggali dan menjaga potensi ini diperlukan perangkat pendukung yang mampu membantu proses eksplorasi tersebut dan salah satunya adalah dengan menggunakan robot ROV. Kebanyakan kegiatan eksplorasi bawah air dilakukan sendiri oleh manusia tanpa bantuan robot, seperti pengamatan bawah laut. Pengamatan bawah laut yang dilakukan sendiri oleh manusia memiliki beberapa resiko yaitu adanya area-area yang sulit dijangkau manusia serta ancaman dari serangan binatang-binatang air berbahaya. Oleh karena itu, untuk memaksimalkan proses eksplorasi bawah air itu diperlukan alat yang mampu bergerak bebas di dalam air, aman dan efisien dalam membantu tugas manusia.

\section{Tinjauan Pustaka}

\section{Robot Bawah Air (Underwater Robot)}

Robot bawah air adalah salah satu tipe robot mobile yang aplikasinya ditujukan untuk melakukan kegiatan di bawah air (www.ilmukelautan.com). Secara umum robot bawah air di kelompokkan atas dua jenis yaitu AUV (Autonomous Underwater Vehicle) dan ROV (Remotely Operated Vehicle). AUV adalah jenis robot bawah air yang bersifat autonomous (otonom), robot dapat bergerak dan melakukan kegiatan sendiri, berdasarkan program yang telah ditanamkan di dalam chip-nya. Hal ini ditunjang dengan dukungan dari sensorsensor yang disertakan pada robot tersebut. Sedangkan ROV adalah robot bawah air yang dikendalikan oleh operator dalam pengoperasiannya, dan didukung oleh perangkat kendali (remote kontrol) dalam pengoperasiannya. Contoh Robot penyelam termasuk dalam jenis robot atau kendaraan bawah air yang tergolong ROV. Robot penyelam adalah 
robot yang mampu bergerak di dalam air. Gerakan yang dapat dilakukan adalah naik dan turun/menyelam. Gerakan ke atas timbul akibat adanya gaya dorong dari putaran propeller, sedangkan untuk gerak menyelam disebabkan oleh berat beban dari robot (saat kondisi motor off).

\section{ROV (Remotely Operated Vehicle)}

ROV (Remotely Operated Vehicle) menurut Marine Technology Society ROV Committee's dalam "Operational Guidelines for ROVs" (1984) dan The National Research Council Committee's dalam "Undersea Vehicles and National Needs" (1996) pada dasarnya sebuah robot bawah laut yang dikendalikan oleh operator ROV, untuk tetap dalam kondisi yang aman, pada saat ROV bekerja di lingkungan yang berbahaya.

ROV seperti pada Gambar 1 secara luas dikenal sebagai nama umum bagi kapal selam mini yang kerap digunakan pada industri minyak dan gas lepas pantai. Kapal selam ini tak berawak, tapi dioperasikan dari kapal lain. Sistem ROV terdiri atas vehicle (atau sering disebut ROV itu sendiri), yang terhubung oleh kabel umbilical ke ruangan kontrol dan operator di atas permukaan air (kapal, rig atau barge). Melalui kabel umbilical, tenaga listrik dan juga perintah-perintah, atau sinyalsinyal kontrol, disampaikan dari perangkat kontrol ke ROV, secara dua arah. ROV dilengkapi dengan peralatan atau sensor tertentu seperti kamera video, transponder, kompas, odometer, bathy (data kedalaman) dan lain-lain tergantung dari keperluan dan tujuan surveinya. Kebanyakan ROV dilengkapi dengan kamera video dan lampu yang digunakan untuk melakukan pengamatan

(observation). Kemampuannya bisa ditingkatkan dengan menambahkan sonar, magnetometer, kamera foto, manipulator atau lengan robotik, pengambil sampel air, dan alat pengukur kejernihan air, penetrasi cahaya, serta temperatur. Kabel-kabel ROV dilapisi dengan tabung penuh minyak agar terhindar dari korosi air laut. Alat pendorong dipasang di tiga lokasi agar menghasilkan kontrol penuh terhadap alat itu. Adapun kamera, lampu, dan lengan manipulator berada di bagian depan atau belakang.

Mengenai siapa yang pertama kali memperkenalkan istilah ROV dan yang membuatnya tidak diketahui secara pasti. Namun setidaknya ada dua peristiwa penting yang berkaitan dengan mulai populernya istilah ROV yaitu ketika diluncurkannya PUV (Programmed Underwater Vehicle) yang dibuat oleh Luppis-Whitehead Automobile (LWA) di Austria pada tahun 1864. Sebutan ROV sendiri pertama kali dibuat oleh Dimitri Rebikoff dalam Marine Technology Society tahun 1953, yang membuat ROV dengan nama POODLE.

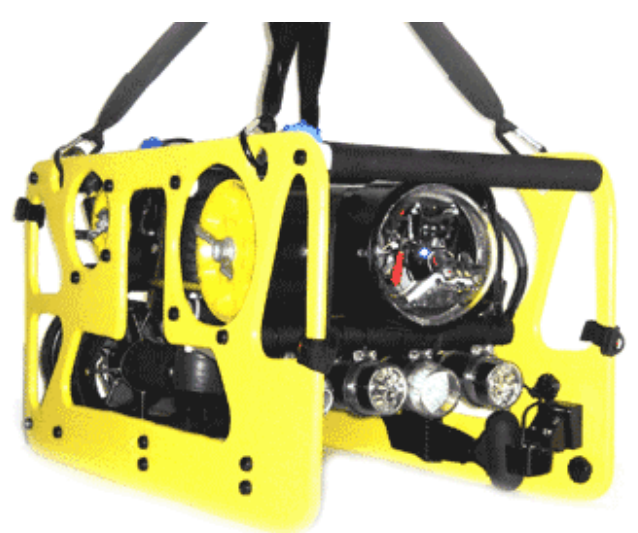

Gambar 1. ROV 
Angkatan Laut Amerika Serikat (AS) selanjutnya mengembangkan teknologi ini. Dengan dukungan teknologi tinggi dan pendanaan besar mereka mengembangkan ROV untuk mengangkat ranjau-ranjau di dasar laut dan peristiwa hilangnya bom atom di Spanyol pada kecelakaan pesawat di tahun 1966. Teknologi ROV ini dikembangkan sejak 1960-an oleh Angkatan Laut Amerika Serikat dengan tujuan awalnya untuk operasi penyelamatan dan pengambilan obyek di dasar laut.

Generasi berikutnya dengan semakin berkembangnya teknologi, ROV banyak digunakan untuk mendukung pekerjaan di pengeboran minyak lepas pantai. RoV pertama kali yang dilibatkan dalam hal pekerjaan tersebut adalah RCV-225 dan RCV-150 yang dibuat oleh HydroProducts, Amerika Serikat. Saat ini, pada saat kecenderungan eksplorasi minyak dan gas semakin banyak dilakukan pada laut dalam, ROV telah menjadi suatu bagian yang penting dari operasional kegiatan ekplorasi tersebut.

ROV terbagi atas berbagai tipe, tergantung dari kemampuan dan fungsi kerjanya. Salah satu tipe ROV dari situs www.ilmukelautan.com yaitu Small Electric Vehicle (ROV Kecil), berdimensi mini untuk kedalaman kurang dari $300 \mathrm{~m}$, biasanya untuk keperluan inspeksi dan pengamatan, digunakan untuk inspeksi perairan pantai, juga untuk ilmiah, SAR, waduk, saluran airdan inspeksi nuklir. Ada juga berdasarkan kemampuan kerjanya seperti tipe Work Class Vehicle, yang menggunakan listrik dan hidrolik sebagai sumber tenaganya. Sebagian besar tipe ini untuk mendukung pekerjaan pengeboran lepas pantai, yang digunakan untuk survey dan rektifikasi pipa gas bawah laut dan kelas inspeksi (inspection-class) dan yang kelas kerja atau (work-class). ROV kelas inspeksi ini kecil dan agak ringan, biasanya digunakan untuk survey dan pekerjaan tes karat (catodhic protection) konstruksi platform dan bangunan air lepas pantai.

Salah satu contoh ROV tipe work class yaitu Venom (Gambar 2). Venom work class ROV didesain untuk operasi bawah air hingga kedalaman 3000 meter dan digerakkan dengan unit tenaga hidrolik untuk menghasilkan daya hingga 150 HP (horse power). Desain yang modular memberikan berbagai mode operasi dan tugas-tugas yang dapat dilakukan dengan sistem tunggal. Hal yang paling penting dalam Venom ialah perawatan dan perbaikan kabel kapal selam. Fasilitas daya, kontrol dan ruang kerja di dalamnya memberikan mobilisasi yang cepat dalam sebuah alternatif kapal selam.



Gambar 2.2 Venom work class ROV Jurnal Sains dan Teknologi |396 


\section{(Sumber: Venom ROV Specifications)}

Sistem ROV pada umumnya bekerja di atas wahana apung seperti kapal, barge, atau rig. Bila sistem ROV dipasang diatas kapal, maka posisi ROV di bawah laut akan mengacu pada titik referensi di kapal. Untuk keperluan survei, kapal biasanya menggunakan DGPS (Differential Global Positioning System) sebagai penentuan posisi utamanya. Sedangkan untuk posisi di bawah laut, sistem ROV dilengkapi dengan alat penentuan posisi bawah laut menggunakan gelombang suara (Acoustic Underwater Positioning).

\subsection{Mikrokontroler MCS-51}

Mikrokontroler MCS-51 adalah keluarga mikrokontroler 8051 yang diperkenalkan pertama kali oleh Intel Corporation. Mikrokontroler MCS-51 standar adalah mikrokontroler 8 bit, dimana bus data internal dan registerregister yang dimilikinya memiliki lebar data 8 bit.

Mikrokontoler MCS-51 memiliki fitur antara lain: $4 \times 8$ bit port I/O, RAM internal 128 bytes, memiliki 2 buah timer, sebuah port serial, kendali interupsi dengan 5 sumber interupsi, dapat mengalamati memori program sampai 64 Kbyte (KB) dan memori data sampai $64 \mathrm{~KB}$, dan register-register khusus (SFR=Special Function Register) seperti akumulator (A), register $B$, stack pointer (SP), data pointer (DPTR), P0, P1, P2, P3 untuk mengakses port $\mathrm{I} / \mathrm{O}$, buffer data serial, register timer, register kendali untuk port serial, timer, dan interupsi (Usman, 2008).

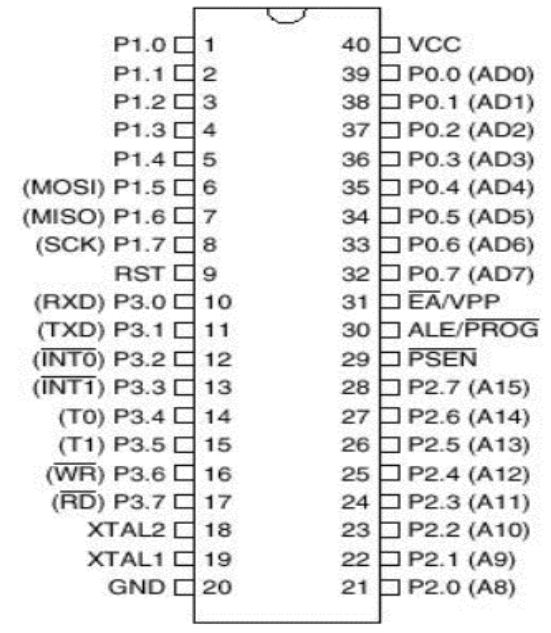

Gambar 3. Konfigurasi PIN MCS-51

Terdapat tiga bagian penting pada mikrokontroler MCS-51, yaitu memori program (flash memory), memori data, dan CPU (Central Processing Unit) yang bertugas membaca memori program dan menjalankan perintah yang tersimpan di dalamnya. CPU ini tersusun oleh sebuah unit aritmetika dan logika (ALU=Arithmethic Logic Unit) yang terhubung dengan SFR yaitu register $A$ $(\mathrm{ACC}=$ accumulator $)$, register $\mathrm{B}, \mathrm{PSW}$ (Program Status Word) dan stack pointer (SP). Dan 16 bit Program Counter (PC) serta Data Pointer (DPTR). Gambar 3 menunjukkan konfigurasi pin mikrokontroler MCS-51.

Susunan pin-pin mikrokontroler AT89C51 diperlihatkan pada Gambar 2 di atas. Penjelasan darimasing-masing pin adalah sebagai berikut :

a. Pin 1 sampai 8 (port 1) merupakan port paralel 8 bit dua arah (inputoutput) yang digunakan sebagai keperluan general purpose.

b. Pin 9 (Reset) adalah interupsi reset (aktif high) perpindahan kondisi 
rendah ke tinggi akan mereset AT89C51. Pin ini dihubungkan dengan rangkaian power on reset.

c. Pin 10 sampai 17 (port 3) adalah port paralel 8 bit dua arah (input-output) yang memiliki fungsi pengganti. Fungsi pengganti meliputi TXD (Transmision Data), RXD (Receiver Data), INT0 (Interupt 0), INT1 (Interupt 1), T0 (timer 0), T1 (Timer 1), WR (Write), dan RD (Read). Bila fungsi pengganti tidak dipakai, pin-pin ini dapat digunakan sebagai port paralel 8 bit serbaguna.

d. Pin 18 dan 19 (XTAL1 dan XTAL2) adalah pin input osilator kristal, yang merupakan input clock bagi rangkaian osilator internal.

e. Pin 20 (ground) dihubungkan ke Vss atau Ground.

f. Pin 21 sampai 28 (port 2) adalah port paralel 8 bit dua arah (input-output). Port 2 ini mengirim byte alamat bila dilakukan pengaksesan memori ekternal.

g. Pin 29 adalah pin PSEN (Program Strobe Enable) yaitu sinyal pengontrol yang membolehkan program memori eksternal masuk ke dalam bus selama proses pemberian/pengambilan intruksi.

h. Pin 30 adalah pin output ALE (Address Latch Enable) yang digunakan untuk menambah alamat memori eksternal selama pelaksanaan intruksi.

i. Pin 31 EA bila pin ini diberi logika tinggi, mikrokontroler akan melaksana-kan intruksi dari ROM ketika isi program counter kurang dari 4096, bila diberi logika rendah maka mikro-kontroler akan melaksanakan seluruh intruksi dari memori program luar. j. Pin 32 sampai 39 (port 0) merupakan port paralel 8 bit open drain dua arah. Bila digunakan untuk mengakses memori luar, port ini akan memultipleks alamat memori dengan data.

k. Pin 40 (Vcc) dihubungkan ke Vcc (+5 $\mathrm{V})$.

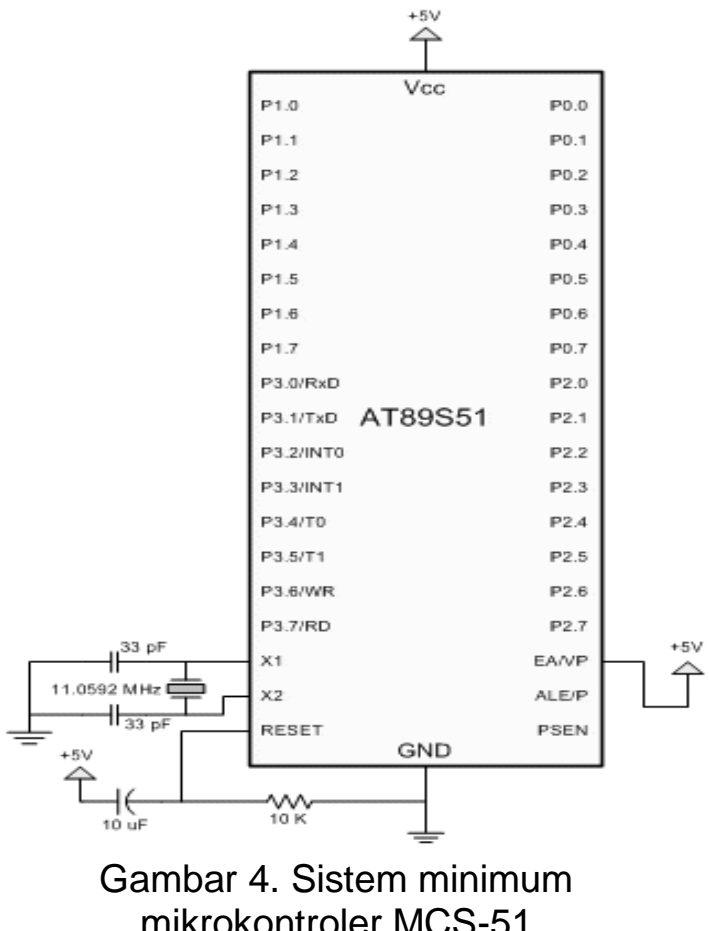

Untuk dapat mengoperasikan mikrokontroler MCS-51, harus dibuat sistem minimum yang meliputi komponen antara lain: sumber tegangan (Vcc), Ground (Gnd), Osilator, dan sistem reset. Dengan sistem minimum ini mikrokontroler MCS-51 sudah dapat diprogram dan dioperasikan. Gambar 4 menunjukkan sistem minimum mikrokontroler MCS-51.

Untuk membuat program mikrokotroler MCS-51 digunakan editor dan compiler untuk bahasa assembler A51 (bahasa assembler mikrokontroler Jurnal Sains dan Teknologi|398 
MCS-51) (Ayala, 1991). Dalam pembahasan ini editor dan compiler yang digunakan adalah M-IDE Studio MCS-51. Setelah proses pembuatan dan kompilasi program selesai dilakukan akan diperoleh file intel hex ( ${ }^{*}$.hex). File ini adalah file yang akan diprogramkan ke mikrokontroler MCS-51. Pemrograman mikrokontroler dilakukan dengan menggunakan perangkat ISP (In System Programmer) Flash Programmer melalui antarmuka port paralel komputer.

\section{METODE PENELITIAN}

Pendekatan dalam penelitian ini menggunakan metode Penelitian dan Pengembangan (Research and Development/R\&D). Sedangkan analisis yang digunakan adalah analisis S.M.A.R.T yaitu Specific, Measurable, Achievable, Realistic dan Time-based. Perancangan penelitian meliputi perancangan hardware dan software. Selain itu dalam metode penelitian ini akan dibahas juga tentang lokasi penelitian, subjek dan objek (peubah yang diamati/diukur), teknik pengumpulan data, analisis data, dan luaran yang dijanjikan.

\section{Metode Penelitian dan \\ Pengembangan (R\&D)}

Menurut Borg and Gall (Borg, 1989), "educational research and development is aprocess used to develop and validate educational product'. Atau dapat diartikan bahwa penelitian pengembangan pendidikan adalah sebuah proses yang digunakan untuk mengembangkan dan memvalidasi produk pendidikan. Hasil dari penelitian pengembangan tidak hanya pengembangan sebuah produk yang sudah ada melainkan juga untuk menemukan pengetahuan atau jawaban atas permasalahan praktis. Langkahlangkahnya seperti pada Gambar 5 . Metode penelitian dan pengembangan juga didefinisikan sebagai suatu metode penelitian yang digunakan untuk menghasilkan produk tertentu, dan menguji keefektifan produk tersebut (Sugiyono, 2011).

Selanjutnya, penelitian pengembangan (R\&D) adalah sebuah strategi atau metode penelitian yang cukup ampuh untuk memperbaiki praktik (Sukmadinata, 2009). Penelitian Pengembangan juga diartikan sebagai suatu proses atau langkah-langkah untuk mengembangkan suatu produk baru atau menyempurnakan produk yang telah ada yang dapat dipertanggungjawabkan (Sujadi, 2002). Sejalan dengan hal tersebut, menurut (Richey, 2007), pengembangan adalah proses penerjemahan spesifikasi desain ke dalam bentuk fisik yang berkaitan dengan desain belajar sistematik, pengembangan dan evaluasi memproses dengan maksud menetapkan dasar empiris untuk mengkreasikan produk pembelajaran dan non-pembelajaran yang baru atau model peningkatan pengembangan yang sudah ada. Untuk dapat menghasilkan produk tertentu digunakan penelitian yang bersifat analisis kebutuhan dan untuk menguji keefektifan produk tersebut agar dapat berfungsi di masyarakat luas maka diperlukan penelitian untuk menguji keefektifan produk tersebut.

Menurut Borg and Gall (1989), ada empat ciri utama dalam metode penelitian dan pengembangan, yaitu: 
1. Studying research findings pertinent to the product to be develop.

Artinya, melakukan studi atau penelitian awal untuk mencari temuan-temuan penelitian terkait dengan produk yang akan dikembangkan.

2. Developing the product base on this findings.

Artinya, mengembangkan produk berdasarkan temuan penelitian tersebut.

3. Field testing it in the setting where it will be used eventually.

Artinya, dilakukannya uji lapangan dalam seting atau situasi senyatanya dimana produk tersebut nantinya digunakan.

4. Revising it to correct the deficiencies found in the field-testing stage.

Artinya, melakukan revisi untuk memperbaiki kelemahan-kelemahan yang ditemukan dalam tahap-tahap uji lapangan.

Dari empat ciri utama R\&D tersebut, memberikan gambaran bahwa ciri utamaR\&D adalah adanya langkahlangkah penelitian awal tekait dengan produk yang akan dikembangkan. Berdasarkan hasil penelitian tersebut kemudian produk pendidikan dirancang dan dikembangkan untuk kemudian diuji dan diperbaiki/direvisi.



Gambar 5. Langkah-langkah penggunaan Metode R\&D menurut Borg dan Gall

Pendekatan (R \& D) dalam penelitian ini meliputi sepuluh langkah. Adapun bagan langkah-langkah penelitiannya seperti ditunjukkan pada Gambar 5 di atas.

Untuk dapat memahami tiap langkah pada gambar di atas tersebut dapat dijelaskan sebagai berikut.

1. Studi Pendahuluan (Research and Information Collecting)

Langkah pertama ini meliputi analisis kebutuhan, studi pustaka, studi literatur, penelitian skala kecil dan standar laporan yang dibutuhkan.

2. Merencanakan Penelitian (Planning)

Setelah melakukan studi pendahuluan, pengembang dapat melanjutkan langkahkedua, yaitu merencanakan penelitian. Perencaaan penelitian $R$ \& $D$ meliputi: 1) merumuskan tujuan penelitian; 2) memperkirakan dana, tenaga dan waktu; 3) merumuskan kualifikasi peneliti dan bentuk-bentuk partisipasinya dalam penelitian.

3. Pengembangan Desain (Develop Preliminary of Product) 
Langkah ini meliputi: 1) Menentukan desain produk yang akan dikembangkan (desain hipotetik); 2) menentukan sarana dan prasarana penelitian yang dibutuhkan selama proses penelitian dan pengembangan; 3) menentukan tahap-tahap pelaksanaan uji desain di lapangan; 4) menentukan deskripsi tugas pihak-pihak yang terlibat dalam penelitian.

4. Uji produk secara terbatas (Preliminary Field Testing)

Langkah ini merupakan uji produk secara terbatas. Langkah ini meliputi: 1)melakukan uji lapangan awal terhadap desain produk; 2) bersifat terbatas, baik substansi desain maupun pihak-pihak yang terlibat; 3) uji lapangan awal dilakukan secara berulang-ulang sehingga diperoleh desain layak, baik substansi maupun metodologi.

5. Revisi Hasil Uji Lapangan Terbatas (Main Product Revision)

Langkah ini merupakan perbaikan model atau desain berdasarakan uji lapangan terbatas. Penyempurnaan produk awal akan dilakukan setelah dilakukan uji coba lapangan secara terbatas. Pada tahap penyempurnaan produk awal ini, lebih banyak dilakukan dengan pendekatan kualitatif. Evaluasi yang dilakukan lebih pada evaluasi terhadap proses, sehingga perbaikan yang dilakukan bersifat perbaikan internal.

6. Uji produk secara lebih luas (Main Field Test)

Langkah merupakan uji produk secara lebih luas. Langkah ini meliputi 1) melakukan uji efektivitas desain produk; 2) uji efektivitas desain, pada umumnya, menggunakan teknik eksperimen model penggulangan; 3) Hasil uji lapangan adalah diperoleh desain yang efektif, baik dari sisi substansi maupun metodologi.

7. Revisi Hasil Uji Lapangan Lebih Luas (Operational Product Revision) Langkah ini merupakan perbaikan kedua setelah dilakukan uji lapangan yang lebih luas dari uji lapangan yang pertama. Penyempurnaan produk dari hasil uji lapangan lebih luas ini akan lebih memantapkan produk yang kita kembangkan.

8. Uji Kelayakan (Operational Field Testing)

Langkah ini meliputi sebaiknya dilakukan dengan skala besar: 1) melakukan uji efektivitas dan adaptabilitas desain produk; 2) uji efektivitas dan adabtabilitas desain melibatkan para calon pemakai produk; 3) hasil uji lapangan adalah diperoleh model desain yang siap diterapkan, baik dari sisi substansi maupun metodologi.

9. Revisi Final Hasil Uji Kelayakan (Final Product Revision)

Langkah ini akan lebih menyempurnakan produk yang sedang dikembangkan. Penyempurnaan produk akhir dipandang perlu untuk lebih akuratnya produk yang dikembangkan. Pada tahap ini sudah didapatkan suatu produk yang tingkat efektivitasnya dapat dipertanggungjawabkan. Hasil penyempurnaan produk akhir memiliki nilai "generalisasi" yang dapat diandalkan. 
10. Desiminasi dan Implementasi Produk Akhir (Dissemination and Implementation)

Laporan hasil dari penelitian ini didesiminasi dan dipublikasi secara ilmiah. Publikasi ilmiah berupa paper berkaitan dengan model prototipe robot ROV dan kinerjanya yang dipublikasikan dalam jurnal terakreditasi.

\section{Rancangan Penelitian}

Prototipe robot AMOBA yang akan dibangun dirancang agar dapat melakukan kegiatan di bawah air dengan efisien dan aman. Ada beberapa hal yang menjadi fokus dalam tahap perancangan robot yaitu desain konstruksi robot, aktuator (komponen mekanis), main circuit (sirkuit elektronik) dan perangkat lunak (software).

Perancangan konstruksi robot berhubungan dengan beberapa komponen yaitu kerangka robot, bagian tabung/tanki (buoyancy), dan body utama robot (waterproof).

Untuk tahap awal, produk yang dirancang yaitu prototipe robot ini, kerangka robot dibuat menggunakan bahan pipa plastik PVC (Polyvinyl Chloride). Alasan penggunaan bahan PVC adalah karena bahan ini bersih, tidak mudah retak, dan mudah pengerjaannya. Kerangka robot didesain dengan dimensi berukuran $40 \mathrm{~cm} \times 26,5$ $\mathrm{cm} \times 28 \mathrm{~cm}$. dinamis. Gambar 6 dan 7 berikut ini adalah rancangan kerangka robot beserta pelampung (buoyancy) dan beratnya akibat gravitasi.

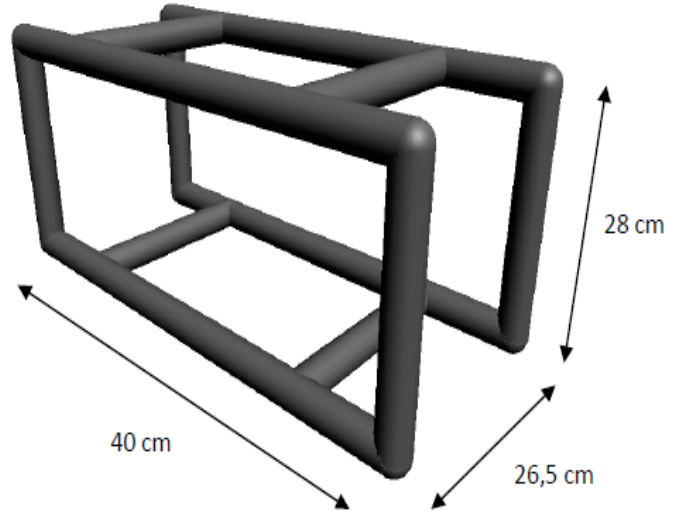

Gambar 6. Rancangan robot



Gambar 7. Gaya Buoyancy dan Gravity

Aktuator adalah komponen yang berfungsi untuk melakukan gerakan mekanis berdasarkan input perintah dari mikrokontroler (processor). Prototipe robot ini memiliki dua komponen mekanis yaitu baling-baling (propeller) dan aktuator kamera.

Propeller adalah baling-baling yang digerakkan dengan tenaga mekanis (motor DC), dan akan mengkonversi gerakan rotasi menjadi daya dorong. Fungsi propeller pada prototipe robot ini adalah sebagai

Jurnal Sains dan Teknologi|402 
penggerak utama, baik gerakan horizontal maupun vertikal. Karena motor DC umumnya tidak tahan terhadap air maka pada penelitian ini digunakan pompa air sebagai penggerak utamanya. Kelemahan pompa air di pasaran adalah terbatas hingga kedalaman tertentu. Gambar 8 berikut adalah pompa air yang digunakan dalam penelitian ini. Pompa air ditempatkan sedemikian rupa sehingga mampu melakukan navigasi di bawah air seperti terlihat pada Gambar 9.

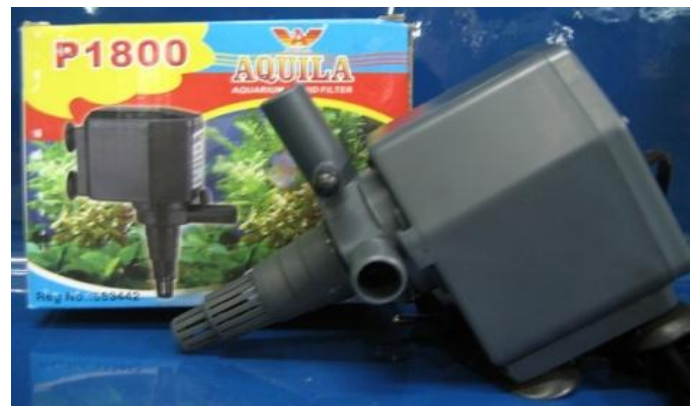

Gambar 8. Jenis pompa air

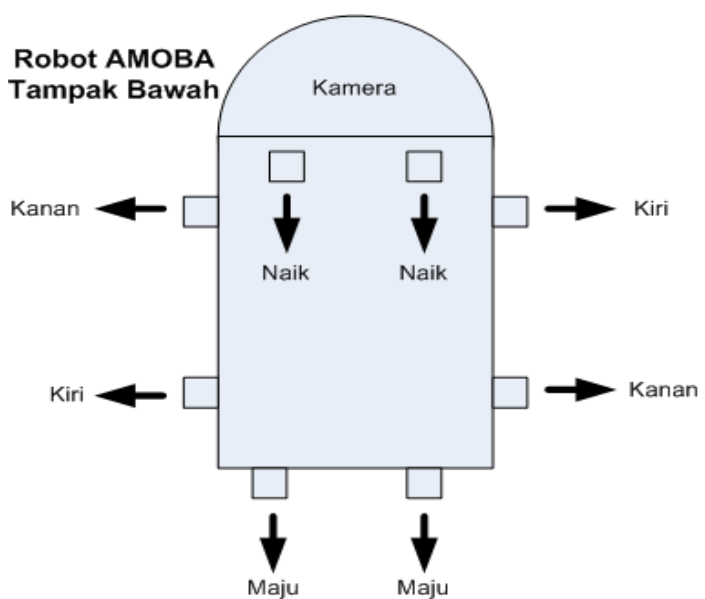

Gambar 9. Penempatan aktuator untuk navigasi robot
Untuk keperluan pengubahan sudut pandang kamera, diperlukan aktuator yang dapat bergerak dalam ukuran sudut tertentu. Contoh aktuator yang beroperasi berdasarkan satuan sudut adalah motor stepper dan motor servo. Oleh karena itu, sebagai aktuator kamera digunakan motor servo, motor ini akan mengarahkan sudut pandang atau posisi kamera pada sudut tertentu.

Ada dua sudut pandang kamera yang harus diatur oleh aktuator kamera yaitu posisi kamera normal dan posisi kamera mengarah ke objek. Sudut pandang normal adalah sudut pandang ketika robot beroperasi dalam fungsi untuk monitoring dan hanya melakukan pergerakan normal. Sedangkan sudut pandang mengarah ke objek digunakan pada saat melakukan suatu pengamatan (observation) objek.

Dalam penelitian ini digunakan IP Camera untuk aktuator kamera karena umumnya IP Camera sudah terdapat motor servo di dalamnya yang dapat digerakkan secara otomatis melalui software yang telah disediakan untuk memudahkan navigasi mengubah sudut-sudut pandang kamera sepanjang $120^{\circ}$ (kiri, kanan, atas, dan bawah). Gambar 10 berikut adalah ip camera yang digunakan dalam penelitian ini.



Support Iphone, Ipad, 3G phone, Smartphone, Wi-fí

Gambar 10. Jenis ip camera 
Mikrokontroler digunakan sebagai pengendali utama robot ini. Mikrokontroler akan memproses input dari perangkat kontrol dan mengontrol semua aktivitas robot seperti pergerakan, sensing, dan komunikasi dengan perangkat kontrol. Rangkaian dasar yang digunakan untuk mengoperasikan sebuah mikrokontroler disebut sebagai rangkaian sistem minimum. Rangkaian sistem minimum terdiri dari rangakaian osilator, rangkaian sistem reset, dan sumber tegangan. Gambar 11 berikut adalah gambar sistem minimum mikrokontroler yang terdiri dari rangkaian osilator dan rangkaian reset. Dan Gambar 12 adalah driver komunikasi serialnya.

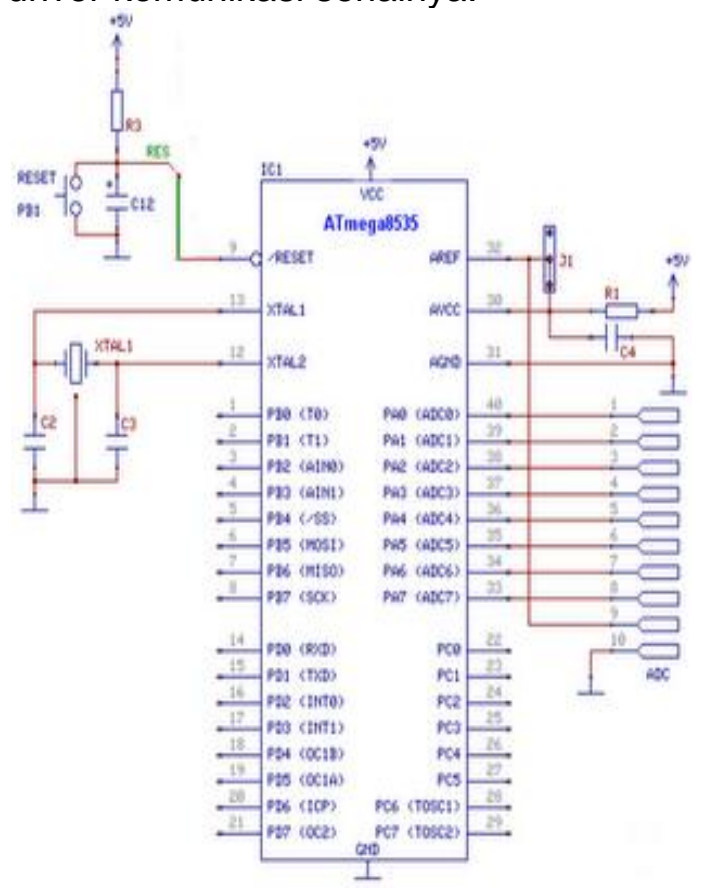

Gambar 11. Rangkaian Sistem Minimum

$\begin{array}{lrr}\text { Perangkat kontrol } & \text { (control } \\ \text { device) adalah perangkat yang } & \text { peran } \\ \text { digunakan untuk mengendalikan robot } \\ \text { secara keseluruhan. Perangkat kontrol }\end{array}$ akan mengendalikan pergerakan robot (horizontal dan vertikal) dan posisi kamera (visualisasi). Perangkat kontrol yang digunakan ada dua jenis yaitu perangkat kontrol utama, digunakan untuk mengontrol pergerakan robot, yang berhubungan langsung dengan main circuit. Dan perangkat kontrol posisi kamera, untuk mengatur pergerakan kamera untuk pengamatan atau observasi. Perangkat kontrol utama menggunakan joystick sebagai pengontrolnya, sedangkan kontrol posisi kamera didapatkan langsung dengan menginstal software dari ip camera.

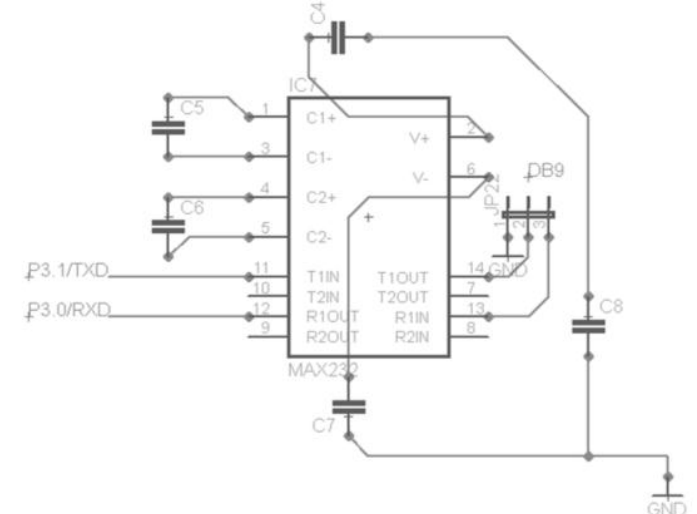

Gambar 12. Driver Komunikasi Serial

Dari beberapa peralatan dan bahan yang dipergunakan dalam penelitian ini, serta modifikasi menyesuaikan bahan yang dipergunakan maka didapatkan hasil perancangan prototipe robot AMOBA seperti terlihat pada Gambar 13. 


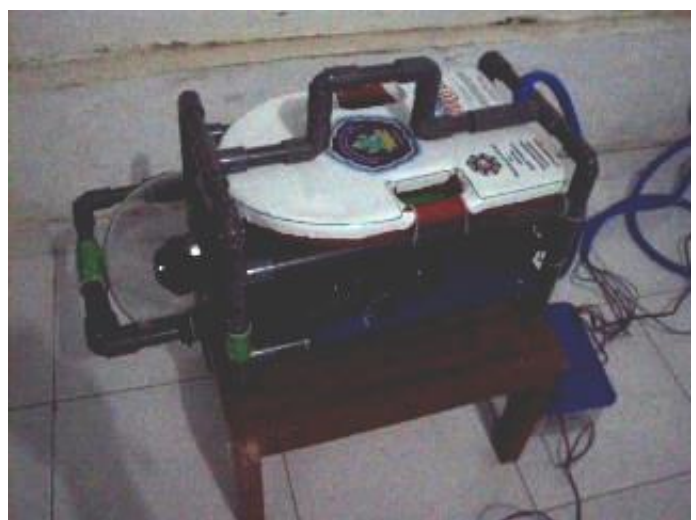

Gambar 13. Rancangan robot riil

Untuk mencapai tujuan
penelitian secara efektif, dalam
penelitian ini diterapkan analisis
menggunakan konsep SMART. Konsep
SMART (specific, measurable,
achievable, realistic, time-based)
pertama kali digunakan oleh George T.
Doran (1981).

\section{HASIL DAN PEMBAHASAN}

Pada penelitian ini akan dilakukan pengujian untuk melihat kinerja komponen-komponen pendukung robot AMOBA yang meliputi :

- Pengujian input kontrol

- Pengujian aktuator pompa air

- Pengujian aktuator kamera

- Pengujian visualisasi kamera

- Pengujian keseluruhan

\section{Pengujian Input Kontrol}

Input kontrol berasal dari penekanan tombol pada joystick yang telah dirancang dengan relay untuk mentransfer tegangan listrik 220VAC ke pompa air melalui kabel pipa sepanjang 20 meter. Kontrol joystick digunakan untuk mempermudah navigasi robot di dalam air. Tombol joystick yang digunakan hanya tombol navigasi saja yaitu atas, bawah, kiri, dan kanan.
Tombol-tombol joystick tersebut menyesuaikan gerak yang dapat dilakukan robot di dalam air akibat semprotan dari pompa air yang diletakkan pada posisi tertentu. Tombol joystick kiri dan kanan akan menggerakkan robot ke kiri dan ke kanan di dalam air. Tombol joystick atas mendorong robot menuju permukaan air. Dan tombol joystick bawah disesuaikan untuk mendorong robot melaju ke depan dengan menyemprotkan air ke belakang robot. Gambar 14 berikut adalah hasil rancangan joystick dan mikrokontroller pengendali utama robot.

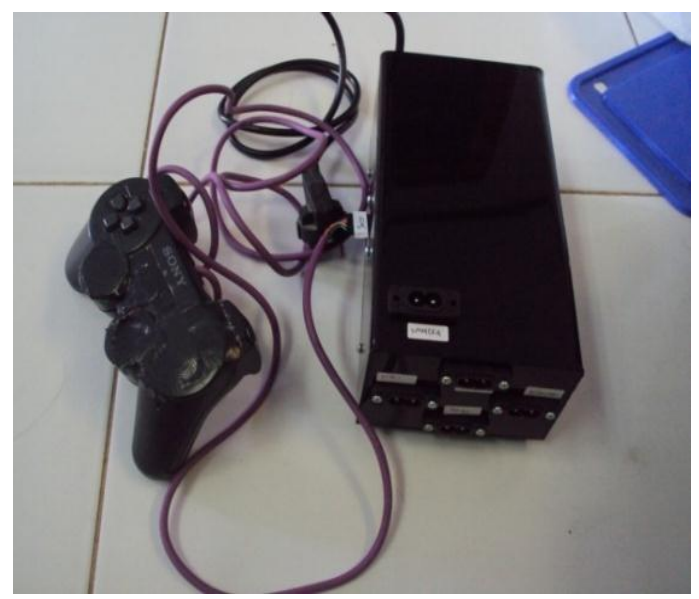

Gambar 14. Rangkaian joystick dan mikrokontroller

\subsection{Pengujian Aktuator Pompa Air}

Aktuator yang diuji terdiri aktuator propeller dengan pompa air. Untuk aktuator propeller dilakukan pengujian untuk pergerakan robot berbelok ke kanan, berbelok ke kiri, maju, dan naik ke permukaan air. Jika perputaran propeller untuk masingmasing pergerakan telah benar dan indikator pengendalian telah berjalan dengan baik, berarti perangkat keras 
propeller dan modul program sudah cukup baik. Jumlah pompa yang digunakan sebanyak 8 buah yaitu : 2 buah pompa untuk berbelok ke kiri, 2 buah pompa untuk berbelok ke kanan, 2 buah pompa untuk maju ke depan, dan 2 buah pompa untuk naik ke atas. Gambar 15 adalah posisi aktuator pompa air.

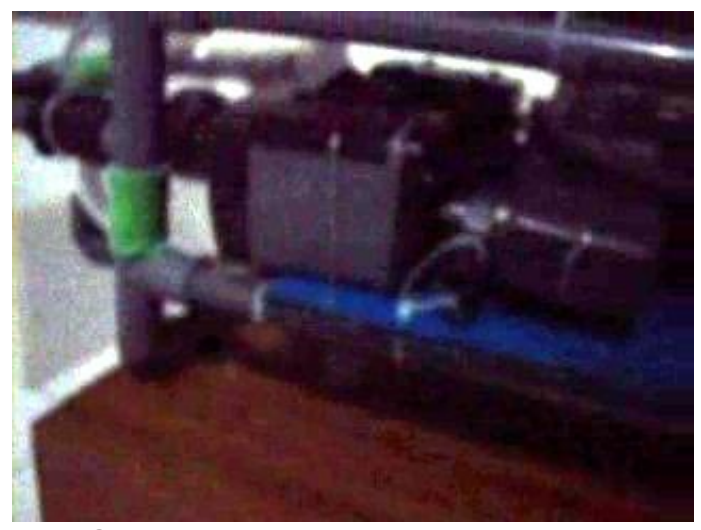

Gambar 15. Aktuator pompa air

\section{Pengujian Aktuator Kamera}

Untuk pengujian aktuator kamera dilakukan dengan memasukkan alamat IP dari ip camera. Selama ip camera menyala, aktuator kamera dan pengaturan lainnya dapat diatur di dalam browser internet dengan memasukkan alamat IP nya. IP camera ada berbagai macam dan merk yang memungkinkan pengendalian aktuator kamera, resolusi, capturing, recording, dan lain-lain dengan spesifikasi yang berbeda-beda. Aktuator ip camera Sun Bio (lihat Gambar 16) pada prototipe robot ini berjalan dengan baik sesuai penekanan tombol melalui software yang dibangkitkan dan ditampilkan ke dalam browser.

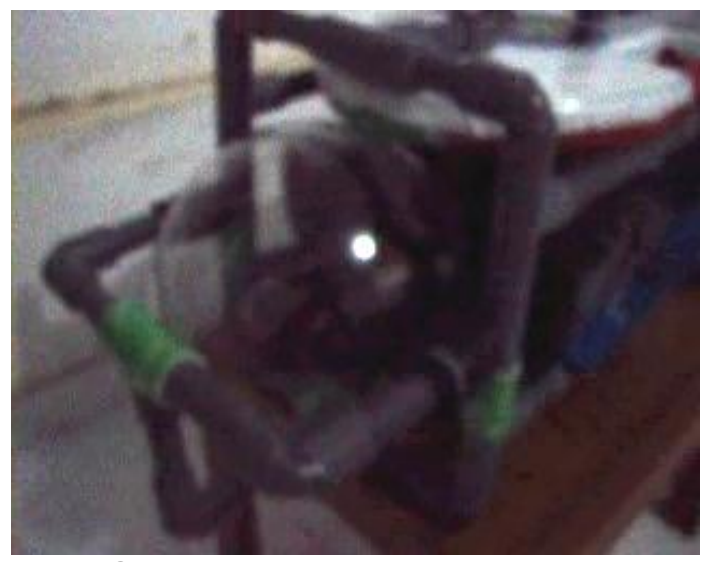

Gambar 16. Aktuator kamera

\section{Pengujian Visualisasi Kamera}

Pengujian visualisasi kamera juga dilakukan dengan cara yang sama seperti aktuator kamera karena menggunakan ip camera. Dengan memasukkan alamat IP dari ip camera ke dalam browser internet yang sudah terhubung dengan kabel utp dari komputer ke ip camera, maka tampilan visualisasi kamera dapat dilakukan (lihat Gambar 17). Proses capture dan recording dapat dilakukan dengan fiturfitur yang telah disediakan oleh ip camera.

Pada tahap pengujian ini juga dilakukan juga pengubahan posisi sudut pandang kamera menggunakan aktuator kamera. Jika proses capture dan pengontrolan posisi kamera telah dapat dilakukan dengan baik, maka diasumsikan perangkat dan program baik untuk digunakan.

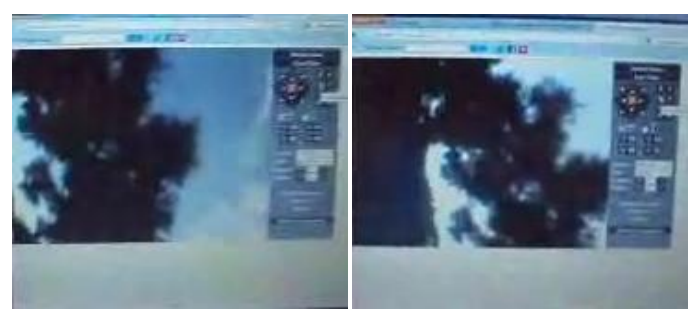

Jurnal Sains dan Teknologi |406 


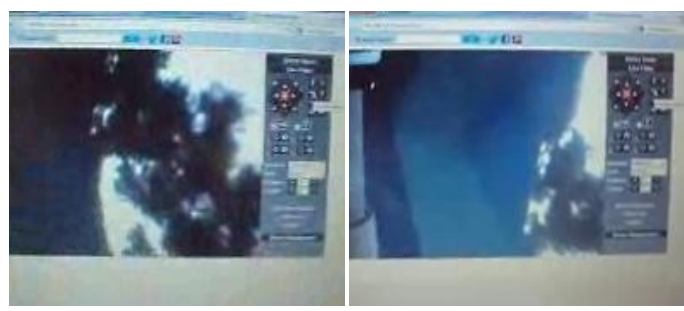

Gambar 17. Visualisasi kamera

\section{Pengujian Keseluruhan}

Pengujian ini bertujuan untuk mengetahui sinkronisasi antara seluruh komponen sistem dalam menjalankan tujuan sistem navigasi, monitoring dan observasi. Pengujian ini memperhatikan proses sistem penggerak (aktuator), pengontrolan, visualisasi dan pergerakkan atau navigasi robot. Dengan pengujian ini maka akan diperoleh hasil kinerja sistem atau robot secara keseluruhan.

Pengujian dilakukan di dua tempat yang berbeda, yang pertama di dalam kolam air dan yang kedua di laut. Pada pengujian pertama didapatkan hasil seperti pada Tabel 1 berikut.

Dari percobaan di atas didapatkan nilai rata-rata kecepatan sekitar 21,5 cm/detik. Hal ini dapat dikatakan cukup lambat karena robot sangatlah berat yaitu $23 \mathrm{~kg}$ sehingga walaupun dibuat mengapung dengan buoyancy yang besar, namun saat gaya dorong awal sangatlah besar sehingga pergerakan di awal pelan kemudian perlahan-lahan cepat. Kecepatan akibat daya dorong air yang dihembuskan pompa air selain tergantung berat robot juga tergantung dari kedalamannya. Semakin dalam robot di air maka tekanan air semakin besar dan berakibat terhentinya pompa air bekerja. Sehingga pada kedalaman tertentu, pompa air sudah tidak bekerja lagi dan hal terburuk dapat menyebabkan kerusakan pompa air. Pompa air yang digunakan memiliki kinerja maksimal untuk kedalaman $3 \mathrm{~m}$, apabila lebih dari $3 \mathrm{~m}$ maka pompa akan tidak dapat bekerja. Untuk kedalaman lebih dari $3 \mathrm{~m}$ dapat menggunakan pompa yang lebih kuat lagi.

Tabel 1. Hasil pengujian kecepatan

\begin{tabular}{|c|l|l|l|}
\hline Pengujian & Kondisi & $\begin{array}{c}\text { Jarak } \\
\text { tempuh }\end{array}$ & $\begin{array}{c}\text { Waktu } \\
\text { tempuh }\end{array}$ \\
\hline 1 & Maju & $8 \mathrm{~m}$ & 32 detik \\
\hline 2 & Naik & $1 \mathrm{~m}$ & 5 detik \\
\hline 3 & Belok Kiri & $8 \mathrm{~m}$ & 38 detik \\
\hline 4 & $\begin{array}{l}\text { Belok } \\
\text { Kanan }\end{array}$ & $8 \mathrm{~m}$ & 40 detik \\
\hline
\end{tabular}

Untuk pengujian kedua terjadi kesulitan pengukuran dikarenakan air laut memiliki arus yang cukup kuat di dalam air laut sehingga hanya dapat diujikan pada air laut yang tenang.

Untuk mencapai tujuan penelitian secara efektif, dalam penelitian ini diterapkan analisis menggunakan konsep SMART. Konsep SMART (specific, measurable, achievable, realistic, time-based) dalam penelitian ini dapat dijelaskan sebagai berikut :

1. Spesifik (Specific)

Tujuan dalam penelitian ini adalah menghasilkan rancangan prototipe robot alat monitor dan observasi bawah air (AMOBA) berbasis ROV yang mampu bergerak di dalam air. Tujuan ini telah tercapai dengan jelas dan spesifik bahwa yang dihasilkan adalah rancangan prototipe robot.

2. Terukur (Measurable)

Pengujian yang dilakukan dalam penelitian ini yaitu mengukur kecepatan rata-rata dari pergerakan robot di dalam air. Dari hasil 
perhitungan

didapatkan

kecepatannya sebesar $21,5 \mathrm{~cm} /$ detik.

Setiap aktuator pompa air memiliki spesifikasi tertentu hal ini juga harus terukur dengan jelas disertai satuannya. Untuk spesifikasi pompa air yang digunakan dalam robot dapat dilihat pada Tabel 2.

Tabel 2. Spesifikasi pompa air

\begin{tabular}{|l|l|c|c|c|c|}
\hline No & \multicolumn{1}{|c|}{ Merk } & Jml & Power & $\begin{array}{c}\text { Tinggi } \\
\text { Maks }\end{array}$ & $\begin{array}{c}\text { Daya } \\
\text { Maks }\end{array}$ \\
\hline 1. & ATMAN AT-104 & 2 & 38 watt & $3,0 \mathrm{~m}$ & $\begin{array}{c}2000 \\
\text { liter } \text { jam }\end{array}$ \\
\hline 2. & Mini JEBO Q112 & 4 & 6 watt & $2,0 \mathrm{~m}$ & $\begin{array}{c}250 \\
\text { liter } / \mathrm{jam}\end{array}$ \\
\hline 3. & ADA W-488 & 2 & $45 \mathrm{watt}$ & $3,0 \mathrm{~m}$ & $\begin{array}{c}3000 \\
\text { liter } \text { jam }\end{array}$ \\
\hline
\end{tabular}

3. Tercapai (Achievable)

Tujuan yang diinginkan dalam penelitian ini telah tercapai, rancangan dan robot riil telah dapat berfungsi sebagaimana mestinya. Tercapainya tujuan penelitian diperkuat dengan pengujianpengujian yang dilakukan.

4. Masuk akal (Realistic)

Tujuan yang ingin dicapai dalam penelitian ini cukup realistis, karena hanya membuat prototipe robot yang mampu memonitor dan mensurvey bawah ini. Untuk saat ini cukup dengan membuat prototipe robot yang nantinya dapat dikembangkan dengan spesifikasi motor yang berbeda, dikembangkan dengan kamera wireless misalnya maupun dikembangkan fungsi-fungsi tambahan lainnya seperti lengan robot, pencahayaan, dan lain-lain.

5. Berdasarkan waktu (Time-Based)

Penelitian ini berlangsung selama 8 (delapan) bulan. Jadwal kegiatan dalam penelitian ini dapat dilihat pada tabel di lampiran tentang jadwal kegiatan penelitian tahun 2013.
Penelitian ini berlangsung dari 1 April hingga 31 Nopember 2013.

Dari beberapa ROV yang dikembangkan di dunia, hasil prototipe robot ini jauh dari sempurna, karena kemampuannya yang terbatas. Namun ini merupakan awal penelitian yang baik untuk menyempurnakan sistem navigasi, sistem kamera, sistem pendorong dan sistem lainnya. Dengan keterbatasan waktu dan dana yang disediakan untuk penelitian ini, maka pengembangan robot ROV hanya menfokuskan pada pola penempatan aktuator pompa air untuk mencapai sistem navigasi yang maksimal, sistem pengendalian robot, serta mengukur kecepatan dan kedalaman yang mampu dicapai dengan pompa air yang ada.

\section{Simpulan dan Saran}

Perancangan dan pembuatan robot prototipe untuk membantu survey bawah air ini dapat disimpulkan berjalan dengan baik dengan pengendalian navigasi yang sesuai harapan. Robot yang diberi nama AMOBA (Alat Monitor dan Observasi Bawah Air) memiliki kemampuan memonitor keadaan air secara visual sehingga dapat memberikan tampilan lingkungan air. Secara umum, alat ini bekerja dengan baik, mampu bernavigasi dan memonitor menggunakan ip camera dengan baik. Dari percobaan yang dilakukan didapatkan rata-rata kecepatan sebesar 21,5 cm/detik. Lambatnya pergerakan robot akibat bobot robot sekitar $23 \mathrm{~kg}$ dan semakin dalam robot bergerak maka semakin lambat pompa air bekerja.

Untuk ke depan diharapkan pompa yang digunakan lebih baik lagi seperti pompa submersible yang Jurnal Sains dan Teknologi |408 
harganya cukup mahal namun dapat bertahan lebih dalam.

\section{DAFTAR PUSTAKA}

Ayala, J. K. (1991). The 8051 Microcontroller Architecture, Programming, and Application. St. Paul: West Publishing Company.

Borg, W.R. \& Gall, M.D. Gall. (1989). Educational Research: An Introduction,Fifth Edition. New York: Longman.

E. Kelner, P.E., Letton-Hall Group. (2012). An ROV-Deployed Deepwater Subsea Sampling System. Offshore Technology Conference (OTC 23412).

Enfang S., Ji Xiangchun, An Yan, Zhao Jingyi. (2005). Design and Implementation of Sonars for Underwater Inspection with ROV. Proceedings od ACOUSTICS 9-11 November 2005, Busselton, Western Australia, pp.491-493.

George T. Doran. (1981). There's a S. M. A. R. T. Way to Write Management Goals and Objectives. Management Review (AMA Forum), pps. 35-36.

Halim, S. (2007). Merancang Mobile Robot Pembawa Objek Menggunakan OOPic-R. Jakarta: Elex Media Komputindo.

Richey, Rita C. Klein. (2007). Design and Development Research. London:Lawrence Erlbaum Associates. Inc.

Sugiyono. (2011). Metode Penelitian Kuantitatif Kualitatif dan R\&D. Yogyakarta: Penerbit Alfabeta.
Sujadi, (2002). Metodologi Penelitian Pendidikan. Jakarta: Rineka Cipta.

Sukmadinata, N. S. (2009). Metode Penelitian Pendidikan. Bandung: Rosda Karya.

Usman. (2008). Teknik Antarmuka dan Pemrograman Mikrokontroler AT89S52. Yogyakarta: ANDI. 